\title{
A Atenção da Equipe a Rede de Suporte de Paciente com Síndrome de Down
}

\author{
Furlan,Taina Cristine; Cavenaghi, Barbara Greghi Reche; Maximo, Luiza Guerra; \\ Barrios, Laura Krapienis \\ Centro de Triagem Neonatal e Estimulação Neurosenssorial — taina.furlan@uol.com.br
}

Introdução: a presença da família é essencial para o desenvolvimento da criança. Nesse sentido, a humanização é uma ação necessária para acolher e incentivar participação dos integrantes. Objetivo: Esse estudo se propõe a investigar se a humanização oferecida a familiares de bebê com Síndrome de Down reflete na organização familiar. Métodos: foi empregada a análise e discussão de caso de bebê com Síndrome de Down atendida no período de um ano e meio ( 4 meses e 2 anos de idade) no Centro de Triagem Neonatal e Estimulação Neurossensorial "Dr. Tatuya Kawakami”, em São Caetano do Sul, São Paulo. como forma de promover a humanização foi realizada as seguintes ações: escuta de fatores vivenciados, esclarecimento de dúvidas, estabelecimento de papéis, organização de atividades cotidianas. a composição familiar era de: mãe, pai, tio, tia, avó e irmã. Resultado: foi observado que através das medidas tomadas, a família pôde estabelecer uma organização referente as atividades de cuidado com a criança que beneficiou-a. As tarefas como levar a criança para a terapia, realizar as orientações necessárias, brincar e alimentar foram manejadas tendo em vista a necessidade da família de se adaptar às novas questões. Conclusão: podemos concluir que a promoção da humanização a rede de suporte do paciente contribui para a reorganização familiar e tratamento do paciente. Inferimos também que a humanização deve se estender a toda a família da criança, oferecendo acolhimento e atenção.

Furlan,Taina Cristine; Cavenaghi, Barbara Greghi Reche; Maximo, Luiza Guerra; Barrios, Laura Krapienis. A Atenção da Equipe a Rede de Suporte de Paciente com Síndrome de Down. In: Anais do Congresso Internacional de Humanidades \& Humanização em Saúde [= Blucher Medical Proceedings, num.2, vol.1]. São Paulo: Editora Blucher, 2014. ISSN 2357-7282

DOI 10.5151/medpro-cihhs-10324 